\title{
Research on the Problem of University Party Affairs Team Professional Construction
}

\author{
Liang Chang ${ }^{1}$, Chunwei Yang ${ }^{2}$ \\ ${ }^{1)}$ School of Physics and Optoelectronic Engineering, Dalian University of Technology, Dalian, Liaoning, China (changl@dlut.edu.cn) \\ ${ }^{2)}$ Faculty of management and Economics, Dalian University of Technology, Dalian, Liaoning, China (yangchunwei@dlut.edu.cn)
}

Abstract - University party affairs staff is an important strength of promoting intension type development of higher education. So, building a high-quality, professional university party affairs work team is a fundamental guarantee to strengthen and improve party construction in universities, and implement the development of higher education goals in the new period. "The ordinary college grassroots organizations of the communist party of China work regulations" puts forward the task team and points out the road for the party work professional construction. Through perfecting the mechanism, cultivating a group of set " research type, learning type, service-oriented type, innovative type, expert type" and "five one" in one of the party work cadre is an effective way to realize the party work team professional construction.

Keywords - university party affairs staff, professionalization, the party work cadre, university party construction

\section{高校党务工作队伍专业化建设问题研究}

\author{
常亮 $^{1}$ 杨春薇 $^{2}$ \\ 1) 大连理工大学物理与光电工程学院，大连，辽宁，中国 \\ 2) 大连理工大学管理与经济学部, 大连, 辽宁, 中国
}

摘 要 高校党务工作队伍是推动高等教育内涵式发展的重要力量。打造一支高素质、专业化的高校党务工作队伍, 是新时期加 强和改进高校党建工作, 实现高等教育发展既定目标的根本保障。《中国共产党普通高校基层组织工作条例》的颁布, 为高校党务工作 队伍专业化建设提出了任务、指明了方向。通过完善专业化建设机制, 培养一批集 “研究型、学习型、服务型、创新型、专家型” 于 一身的“五维一体”式的高校党务工作骨干，是实现高校党务工作队伍专业化建设的有效途径。

关键词＼cjkstart高校党务工作队伍，专业化，党务工作骨干，高校党建

\section{1. 引言}

高校党务工作者是高等学校不断加强和改进党建工作 水平, 切实执行党在高等教育领域内各项政策、方针和理 念, 并面向广大师生开展思想政治教育工作的具体实践者; 是社会主义核心价值观在高校中的忠诚捍卫者; 是共产主 义理想和信念的坚定笃信者与传播者。多年来, 这支队伍 在开展高校党的建设、推动高校科学发展、维护高校稳定 等工作中发挥了重要、积极和不可或缺的作用。

大连理工大学 2013 年度党建研究课题支持(项目号: DUTDJ1314); 大连理工大学 2013 年工运理论和工会发展研究重点课题支持。
党的十八大以来, 我国高等教育事业进入了内涵式发 展的历史进程之中, 新的形势要求广大高校党务工作者必 须牢记使命, 与时俱进地把握住高校党建工作面临的新发 展、新趋势, 并以党务队伍自身的 “专业化” 建设为目标, 努力提高工作能力与业务素质。同时, 只有高校党务工作 队伍 “专业化” 能力和素质得到全面的发展, 才能够在新 形势下把高校党建工作推向更高的境界和水平, 使高校党 建不断迸发出新的活力和生命力, ${ }^{[1]}$ 为有中国特色的高等 教育事业发展提供源源不断地思想保证、政治保证和组织 保证。所以, 加强高校党务工作队伍的 “专业化” 建设, 是今后相当长的一段时间内, 高校党建工作的重中之重。 
高校党务工作队伍的 “专业化” 建设问题, 是新形势 下高校党建面临的一项时代课题; 这支队伍的专业化程度 如何, 将直接关系到高校党建和高等教育事业发展的质量 和成效。文章从高校党务工作队伍 “专业化” 建设的定义 与内涵、存在的问题与困难、专业化建设的紧迫性与必要 性、专业化建设的目标与原则、专业化建设的内容和途径 等入手, 逐一分析和探讨, 力争归纳、总结并提出高校党 务工作队伍 “专业化” 建设的措施和方法, 以期为各级教 育行政部门和高等学校党政领导决策提供有价值的参考和 建议。

\section{2. 新时期高校党务工作队伍肩负的历史使命}

党的十八大报告对高等教育赋予了新的历史使命和丰 富的内涵。坚持和发展中国特色社会主义, 需要高等教育 更加深入地贯彻落实科学发展观, 全力推动协调发展、内 涵发展、特色发展、创新发展、开放发展和可持续发展, 积极探索中国特色社会主义高等教育发展道路。全面建成 小康社会的目标要求, 需要高等学校主动把握重要的战略 机遇期, 更好地发挥科技第一生产力和人才第一资源重要 结合点的作用, 引领和带动中国高等教育实现现代化。同 时, “五位一体” 的中国特色社会主义事业总体布局, 需要 高等学校更好地发挥人才培养、科学研究、社会服务和文 化传承与创新这四大功能, 并为国家的现代化建设提供强 有力的人才保障和智力支撑。加快转变经济发展方式, 着 力实施创新驱动发展战略, 需要高等学校更加主动、自觉 地坚持以人为本的核心立场, 培养更多更好的高素质创新 人才, 提升服务国家工业化、信息化、城镇化、农业现代 化同步发展的能力 ${ }^{[2]}$ 。可以说, 高等学校能否完成党中央 赋予的历史使命和发展目标, 确保党对高等教育的绝对领 导, 建立一支高素质、专业化的研究型高校党务工作队伍 是关键。

新时期, 高校党的建设与事业发展对高校党务工作队 伍提出了更高的要求, 建设一支党性强、素质高、业务精、 服务和创新意识突出的党务工作队伍已成为当务之急。但 是, 高校党务工作队伍专业化建设的水平和程度, 尚不能 满足高校党建和高校事业发展的需求。同时, 在《中国共 产党普通高校基层组织工作条例》 (以下简称《条例》) 颁 布后, 关于高校党务工作队伍专业化建设方面的研究成果 非常有限, 上级组织与《条例》相配套的文件与细化制度 也尚未出台, 这些因素均使得高校党务工作队伍专业化建 设工作长期处于 “有声音、有期盼, 无方案、无行动” 的 状态。所以, 深入研究、探索新时期高校党务工作队伍 “专 业化” 建设的新路子, 构建并完善相关机制, 切实建设好 与高等教育内涵式发展目标相适应的 “专业化” 的高校党
务工作队伍, 是高校党建理论创新与实践发展的必然要求, 值得深入研究。

\section{3. 高校党务工作队伍 “专业化” 建设的内涵}

所谓 “专业化” , 是在管理学领域被提及、强调和运 用得最多的基本概念之一。高校党务工作队伍 “专业化” 则是管理学领域的 “专业化” 概念在高校党建及党务队伍 建设领域的具体延伸。

管理学中的 “专业化” 是指个人或组织（团体）逐渐 符合专业标准的成长和发展过程, 是一个需要经历成长、 成熟直至经历挫折而走向成功的检验过程。“专业化” 建 设具有以下几个特征：一是有专门的组织; 二是有特定的 组织目标; 三是有具备服务理念和职业伦理的专业人员, 且这些专业人员经过长期的培养与训练, 熟练运用专门知 识与技能, 并不断提高素质以实现对组织的管理; 四是组 织管理中体现以人为本的人性化原则, 以实现将 “粗放化” 管理转变为 “精细化” 管理; 五是有完善的制度体系; 六 是有具体的评价标准; 七是得到社会的广泛认同。由此可 见, 在研究和探索高校党务工作队伍 “专业化” 建设问题 的过程中, 管理学领域对 “专业化” 概念的理解和系统阐 述, 为高校党务工作队伍的 “专业化” 建设提供了科学思 路，非常具有启发性。

结合高校党建工作的实际, 高校党务工作队伍 “专业 化” 建设的内涵可理解为: 在高校各级党的组织中, 经过 一系列的专业训练、能力培养、工作实践, 并在高校党建 理论领域具备完善的知识结构, 具有很强的科研素养和研 究能力, 以及具备独自处理高校各级党组织的日常性党务 工作的专职或兼职党务工作人员。同时, 在具体的工作和 理论研究中, “专业化” 的高校党务工作者能够按照《党 章》和文件规定, 坚持以马克思主义科学理论为指导, 灵 活地运用党的知识和基本理论, 及时有效地处理高校党建 和师生思想政治教育工作中可能出现的新情况、新问题, 坚持理论研究与工作实践相结合, 努力成为高校党务工作 和高校党建理论创新的行家里手。

\section{4. 高校党务工作队伍现状及 “专业化”建设面临的问 题}

一项涉及全国 21 所大学的高校党务工作队伍现状问 卷调查显示: 当前高校党务工作队伍中约有超过 $70 \%$ 的同 志年龄段集中在 35-40 周岁期间, 队伍年轻化趋势显著, 同时这支队伍对其职业发展需求和诉求也非常旺盛; 党务 队伍中具有硕士及以上学位的人员比例达到了 $65.15 \%$, 特 别在一些 “985” 高校中, 拥有博士学位的人员比例更高, 显示出该支队伍具有较高的学历水平和知识结构, 这就为 
队伍的 “专业化” 建设奠定了学历、知识和综合素质的基 础; 队伍中 $57.58 \%$ 的同志从事高校党务工作的时间达到或 超过 3 年, 体现了这支队伍具有较高的稳定性, 也一定程 度反映出该支队伍的整体流动性较小, 发展 “出口” 较窄; 近 3 年来没有参与过党建理论研究或只参与过 1 项的人员 比例达到 76. $26 \%$, 反映出该支队伍参与党建理论研究的积 极性不高; 高校党务工作人员最希望参加培训的内容位于 前三位是：学历或专业知识提升 (37.6\%)、工作技能提高 (28. $0 \%$ ) 和实践能力发展 $(25.6 \%)^{[3]}$ 。

通过调研, 也发现了高校党务工作队伍建设过程中出 现的一些现象和问题, 主要表现为: 一是高校党务工作者 间的素质和能力存在不均衡, 部分同志的责任心、工作作 风、基本素质与工作能力存在不足; 二是部分高校领导和 师生对党务工作的重视程度不够, 没有树立起将党务工作 与教学科研工作置于同等重要的意识; 三是普遍缺乏党务 工作队伍 “专业化” 建设的配套机制, 尤其在职称、职级 评定, 学习、进修与业务能力培训, 收入待遇与评选表彰 等方面; 四是部分党务工作者的职业认同感不强, 缺乏职 业归属感和职业自豪感; 五是高校党务工作队伍的 “职业 发展链条” 短, 发展空间有限、队伍流动慢。

\section{5. 高校党务工作队伍 “专业化” 建设的对策与途径}

高校党务工作队伍 “专业化” 建设是一个多维度发展 的系统工程。工作中, 可以从推动高等教育内涵式发展目 标出发, 充分考虑到新时期高校党建的任务和需求, 以及 高校党务工作队伍的构成情况和队伍特点, 通过调研和实 践, 科学制定并出台一系列完善的激励与保障机制, 通过 培养一批 “研究型、学习型、服务型、创新型、专家型” 的高校党务工作骨干, 作为高校党务工作队伍 “专业化” 建设的突破口。

5.1 以《条例》为依据, 创造性地开展高校党务队伍 “专 业化”建设实践

《中国共产党普通高校基层组织工作条例》辅导读本 指出 “党务工作者是做好高校党建工作的骨干力量, 造就 一支能担当重任的高素质党务工作队伍, 是全面加强高校 党建工作的必然要求”, 而实现党务工作队伍 “专业化”, 则是适应高校党建发展要求的必然途径。为此, 《条例》中 明确指出: “高等高校应当将党务工作和思想政治工作以及 辅导员队伍建设纳入高校人才队伍建设总体规划, 建立一 支以专职人员为骨干、专兼职干部相结合的党务工作和思 想政治工作队伍。” 同时, “完善政策措施和激励机制, 切 实关心、爱护党务工作者和思想政治工作者, 为他们成长 成才创造条件。”
5.2 不断明晰高校党务工作队伍 “专业化” 建设的指导思 想、目标与原则

以党的十八大精神为指导, 以《条例》为指南, 紧紧 围绕促进高等教育内涵式发展这个中心; 结合高校党建工 作实际, 努力建设一支党性强、素质高、业务精、服务和 创新意识突出的专业化的党务工作队伍。同时, 还要本着 解放思想、讲求创新的精神, 培养和造就一支 “研究型、 学习型、服务型、创新型、专家型” 高校党务工作队伍。 工作中, 高校党委要抢抓机遇、科学谋划, 以高校实施 “人 才强校” 战略为契机, 将高校党务工作队伍纳入到高校人 才建设总体规划, 建立和完善激励保障机制, 打通高校党 务工作队伍在职称、职务方面的 “双向” 发展通道, 支持 和鼓励有条件的党务工作骨干立足本职岗位, 苦练内功、 增强素质, 成为高校党建理论研究与党务工作实务领域的 专家。

\section{3 高校党务工作队伍 “专业化” 建设的内涵与任务}

高校党建的核心是队伍建设, 而队伍建设的关键是“专 业化” 建设。 ${ }^{[4]}$ 高校党务工作队伍的 “专业化” 建设内容 主要包括以下四个方面:

第一方面, 高校党建理论系统化。高校党务工作队伍 专业化建设, 需要系统化的党建理论来指导。面对高校党 务工作队伍专业化建设的新形势、新要求、新情况、新问 题, 现有的党建理论逐渐暴露出零散性、功能单一、理论 不完备、缺乏系统性等问题, 严重制约着高校党建工作创 新与实践, 直接影响到了高校党务工作队伍专业化建设的 进程。因此, 需要高度重视和大力推进高校党建理论系统 化建设。

第二方面, 高校党建理论科学化。高校党建科学化的 内涵是指以马克思主义世界观、方法论和在实践中发展起 来的有中国特色社会主义理论为指导, 以辩证唯物的视角 审视世情、国情、党情、教情和校情的客观变化, 以改革 创新的精神探索新时期高校党建工作的基本规律, 不断创 新工作机制、改进工作方式, 不理将高校党的建设纳入到 科学化的发展轨道。

第三方面, 高校党务工作队伍专职化。党务工作必须 要有一支具有坚强战斗力的工作队伍。《条例》指出 “建立 一支以专职人员为骨干、专兼职干部相结合的党务工作和 思想政治工作队伍。”这就要求在专业化建设过程中, 应遵 循高校党建工作的发展规律, 努力建设一支以专职人员为 主, 专兼结合的高校党务工作队伍。可以说, 党务工作队 伍的专职化是实现 “专业化” 的前提和基础。 
第四方面, 高校党务管理科学化。在工作实践中, 高 校党务工作者要认真研究、借鉴不同学科中先进的管理理 念, 并充分认识到社会信息化、政治民主化、文化多元化 等趋势对高校党建工作带来的影响, 结合高校党建工作特 点在实践中创造性地加以运用, 以实现高校党务工作方式、 方法上的现代化。

5.4 培养 “五维一体” 的党务工作骨干, 是实现 “专业化” 建设的有效途径

所谓 “五维一体”, 是指通过出台一系列的激励保障制 度和系统化的培养体系, 使高校党务工作队伍中的骨干有 条件、有机会发展成为 “研究型、学习型、服务型、创新 型、专家型” 的复合型党务工精英, 以此拓展高校党务工 作队伍 “专业化” 建设途径。

在中国, 推动高等教育内涵式发展、把握和掌控高校 意识形态主导权, 要求中国的一流大学必须同时拥有一支 高水平的研究型高校党务工作队伍。所谓 “研究型党务工 作者”, 是指在具有良好教育背景和学历结构的基础上, 具 有坚实的基础知识、系统科学的研究方法、高水平的研究 能力和创新能力, 在高校党建领域从事研究、实践和创新 工作的专门人才。研究型党务工作者要面向高校党建理论 与实践发展前沿, 在基础性、战略性、前瞻性领域取得突 破。

所谓 “学习型党务工作者”, 是指树立终身学习理念, 通过不断学习获得党建与思想政治教育、社会科学等多方 面的知识; 以不断完善自己、强化自身素质和提升党务工 作能力为主要目的, 将学习内化为一种成长责任、生存方 式和精神追求。

所谓 “服务型党务工作者”, 是指在工作中坚持全心 全意为人民服务, 坚持党的群众路线, 真诚倾听群众呼声, 真心反映群众愿望, 真情关心群众疾苦, 多为群众办好事、 办实事, 努力做到 “权为民所用、情为民所系、利为民所 谋”, 并善于将高校党的基层组织打造成一个体现党性、连 接民心的服务平台。

所谓 “创新型党务工作者”, 是指在拥有过硬的政治素 质、完善的知识结构、坚实的理论基础和丰富的实践经验 基础上, 那些富于开拓精神、具有创造能力、善于创新, 并对高校党建工作做出创造性贡献的党务工作者。
所谓 “专家型党务工作者”, 是指在党的专业知识和党 务工作技能方面, 体现出更高的水平和更优的工作效果的 专门人才。一般而言, 专家型党务工作者在处理新问题、 新矛盾和突发事件时, 能够以新颖和适当的方法有效、及 时地解决问题。

\section{6. 结论}

在研究高校党务工作队伍 “专业化” 建设机制问题的 过程中, 应将重点集中在如何提升党务工作队伍自身素质 和建立完善保障机制这两个关键环节上。一方面, 党务工 作队伍要发展、要政策、要待遇, 必须具备高水平业务素 质和极强的工作能力, 并取得公认的、令人信服的工作业 绩, 这就要求高校党务工作队伍必须着眼于通过 “苦练内 功”, 以实现能力素质的改善、提高与升华。另一方面, 教 育行政部门和高等学校应当摒弃 “等、靠、要” 的思维定 式, 加紧制定、创新、出台符合不同地方和学校发展需要 的政策措施, 同时还要协调和处理好党委与行政、老政策 与新政策、机关与基层、老同志与年轻同志, 以及协调高 校中不同工作系统与系列人员之间的关系等多重问题。

\section{参考文献(References)}

[1] Y. H. Wang, "college party affairs worker ability quality and practice of the path of ascension with the new situation," School party construction and ideological education, vol.5, pp.32-33, 2011.

[2] Y. B. Du, "Comprehensively promote the development of higher education connotation, the education ministry study and implement the spirit to expand the Party's 18 speech at the meeting,"

http://www.moe.edu.cn/publicfiles/business/htmlfiles/moe/ moe_176/201211/144828. Html, 2012-11-18.

[3] Y. P. Wang, "university party cadres construction present situation and countermeasure research in Guangxi," School party construction and ideological education, vol.11, pp.24-35, 2012.

[4] S. Z. Zhang, J. D. Liu and H. R. Du, "The party cadres of colleges and universities specialized construction research," School party construction and ideological education, vol.4, pp.27-29, 2009. 